Check for updates

Cite this: RSC Adv., 2017, 7, 29985

Received 20th April 2017

Accepted 3rd June 2017

DOI: $10.1039 / \mathrm{c} 7 \mathrm{ra04460g}$

rsc.li/rsc-advances

\title{
Synthesis and catalytic activity of palladium supported on heteroatom doped single-wall carbon nanohornst
}

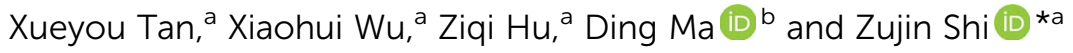

The dehydrogenation of indoline to indole is a vital chemical transformation because of the versatile application of indole as an intermediate in the synthesis of medicines or fine chemicals. As a consequence, various approaches are being explored to catalyze dehydrogenation of indoline. Here, we provided a new strategy for dehydrogenation of indoline. Pd nanoparticles supported on boron-, oxygen-, nitrogen- and phosphorus-doped single-wall carbon nanohorns (CNHs) without ligands were synthesized via a one-step ultrasonic method. Pd nanoparticles with a diameter of 2-3 $\mathrm{nm}$ were dispersed uniformly on heteroatom-doped $\mathrm{CNHs}$. The as-prepared $\mathrm{Pd}-\mathrm{OCNH}$ ( $\mathrm{Pd}$ nanoparticles supported on oxygen-doped $\mathrm{CNH}$ ) exhibited excellent performance as the catalyst in dehydrogenation of indoline at a low temperature due to a synergistic effect between metal palladium and oxygen-doped $\mathrm{CNHs}(\mathrm{OCNHs})$. In the process, metal palladium offers the main active site for adsorption of indoline, and OCNHs not only act as a carrier, but also provide the active groups (ketonic $\mathrm{C}=\mathrm{O}$ ) for $\mathrm{C}-\mathrm{H}$ activation of reactants to improve the catalytic activity. $\mathrm{Pd}-\mathrm{OCNHs}$ could open up a novel way to the dehydrogenation of other heterocycles.

\section{Introduction}

Indole is of great importance for the synthesis of medicines, agrochemicals and fine chemicals as a versatile and significant intermediate. ${ }^{\mathbf{1}}$ Research into methodologies for indole synthesis is ongoing, and direct dehydrogenation of indoline to indole is the simplest and most effective method among those reported. ${ }^{2}$ Dehydrogenation of indoline conventionally needs various oxidizing regents, such as trichlorocyanuric acid, ${ }^{3} \mathrm{~N}$ tert-butylphenylsulfinmidoyl chloride, ${ }^{4}$ and manganese dioxide, ${ }^{5}$ which are often toxic and harmful, and required in considerable amounts. Researchers have also used Ru-based catalysts $\left(\mathrm{Ru} / \mathrm{Al}_{2} \mathrm{O}_{3},{ }^{6} \mathrm{Ru} / \mathrm{Co}_{3} \mathrm{O}_{4},{ }^{7} \mathrm{Ru}(\mathrm{OH})_{X} / \mathrm{Al}_{2} \mathrm{O}_{3},{ }^{8}\right.$ et al. $)$, Aubased (e.g. AuNPs $/ \mathrm{C}^{9}$ and $\mathrm{Au} / \mathrm{CeO}_{2}$ (ref. 10)) and Pd-based counterparts (e.g. Pd-hydroxyapatite ${ }^{\mathbf{1 1}}$ and $\mathrm{Pd}_{3} \mathrm{~Pb} / \mathrm{Al}_{2} \mathrm{O}_{3}$ (ref. 12)) for dehydrogenation of indoline and obtained high yields. Although most of these catalysts avoided stoichiometric and environmentally-hazardous oxidants, they need harsh conditions, involving either extra oxidants $\left(\right.$ e.g. $\left.\mathrm{O}_{2}\right)$ or shielding gas (e.g. $\mathrm{N}_{2}$ ) during the reaction process.

\footnotetext{
${ }^{a}$ Beijing National Laboratory for Molecular Science, State Key Lab of Rare Earth Materials Chemistry and Applications, College of Chemistry and Molecular Engineering, Peking University, Beijing 100871, P. R. China.E-mail: zjshi@pku.edu.cn ${ }^{b}$ Beijing National Laboratory for Molecular Science, College of Chemistry and Molecular Engineering, Peking University, Beijing 100871, P. R. China

$\dagger$ Electronic supplementary information (ESI) available: More characterizations of samples. See DOI: $10.1039 / \mathrm{c} 7 \mathrm{ra} 04460 \mathrm{~g}$
}

Recently, carbon materials (e.g. carbon nanotubes (CNTs) ${ }^{13}$ and nitrogen-doped graphene (NGr-C) ${ }^{\mathbf{1 4}}$ ) as catalyst support were used for dehydrogenation of indoline. For instance, ironnitrogen-doped graphene obtained high conversion and yield by using air (15 bar) as a sole oxidant. In this catalytic system, the catalysts synthesis need pyrolysis at high temperature (800 ${ }^{\circ} \mathrm{C}$ ) and volume of air required was controlled precisely during catalytic process. In addition, the preparations of carbon materials (CNTs and N-doped graphene) are expensive for mass productions and may introduce metal-impurities due to usage of metal catalysts. ${ }^{15}$ The metal-impurities in CNTs are difficult to be removed absolutely, which makes it difficult to identify the nature of proposed synergistic effects. It is noteworthy that single-wall carbon nanohorns (CNHs), an another carbon nanomaterial, could be produced in large scale without using costly metal catalysts by direct current arc discharge method, which makes it cost-effective and metal-free. ${ }^{\mathbf{1 6}}$ Herein, we provide a new catalyst support for dehydrogenation reaction of indoline and achieve a high yield only using air, avoiding amount control of air.

CNHs is similar to single-wall carbon nanotubes (CNTs) in structure, but ends up with horn-shaped caps at one end. ${ }^{17} \mathrm{~A}$ single carbon nanohorn has a nanotubular structure with a length between $30-50 \mathrm{~nm}$ and diameter ranging from 2$5 \mathrm{~nm} .{ }^{18} \mathrm{CNHs}$ always forms three kinds of aggregates with diameter about 50-100 nm, ${ }^{19}$ including dahlida-, bud- and seedtype. ${ }^{20}$ Interestingly, heated in oxygen at $693 \mathrm{~K}$ or in the presence of nitric acid, CNHs could be oxidized to open the 
nanohorns and create nanowindows on the wall, ${ }^{21-23}$ which could prevent the metal nanoparticles (NPs) from sintering and deteriorating, ${ }^{24}$ and eventually let NPs enter inside of the CNHs via holes on the tube wall. ${ }^{25}$ Therefore, CNHs with large surface areas and nanoscale pores is expected to be excellent catalyst support for metal NPs.

Metal supported on CNHs have been widely studied in adsorption, ${ }^{26}$ gas storage, ${ }^{27}$ drug delivery ${ }^{28}$ and catalysts. ${ }^{29-31}$ Specially, CNHs often was used for support of palladium nanoparticles (Pd NPs) ${ }^{22}$ to prevent from aggregation of Pd NPs and formation of catalytically inactive palladium black. ${ }^{32} \mathrm{Pd}$ NPs supported on CNHs have been found to be highly efficient in catalysing $\mathrm{H}_{2}-\mathrm{O}_{2}$ gas phase reaction, water formation reaction and $\mathrm{C}-\mathrm{C}$ coupling reactions such as Heck, Suzuki and Stille reaction in the liquid phase..$^{33-35}$ However, the preparation methods reported generally required heating at relatively high temperature and ligands such as poly(vinylpyrrolidone) (PVP), ${ }^{22,24,33}$ sodium dodecyl sulphate (SDS ${ }^{34}$ and triphenylphosphine $(\mathrm{PPh})^{36}$ to connect metal and CNHs, or stabilize and disperse Pd NPs, which could inhibit the catalytic activity. ${ }^{\mathbf{3 6}}$

In this work, we provide a preparation method for Pd NPs supported on heteroatom doped CNHs without the ligands via one-step reduction under a mild condition. To our best acknowledge, Pd NPs loaded on the different single-atom doped CNHs, Pd-XCNHs (X, doping atom: B, N, O or P) without ligands have been rarely synthesized and their catalytic properties in dehydrogenation of indoline have not been reported yet. The amazing catalytic activity of Pd-XCNHs for dehydrogenation of indoline could make it suitable to be applied to dehydrogenation of other heterocycles.

\section{Experiment}

\section{Synthesis of doped CNHs}

Pure CNHs was prepared by DC arc-discharge method according to our previous report. ${ }^{37} \mathrm{BCNHs}$, NCNHs and PCNHs were produced by DC arc-vaporization of a $\mathrm{B}_{4} \mathrm{C}$-containing, melamine-containing and $\mathrm{PPh}_{3}$-containing composite carbon rod in 400 Torr pressure of $\mathrm{CO}$, respectively. ${ }^{38}$ The rough carbon materials were roasted at $430{ }^{\circ} \mathrm{C}$ for $1 \mathrm{~h}$ in the air to remove the amorphous carbon. CNHs was oxidized by a mixture of concentrated acid (the volume ratio of $\mathrm{H}_{2} \mathrm{SO}_{4}$ and $\mathrm{HNO}_{3}$ is $3: 1$ ) for $3 \mathrm{~h}$ to obtain O-doped CNHs (OCNHs). ${ }^{39}$

\section{Preparation of catalysts}

Pd-XCNHs ( $\mathrm{X}=\mathrm{B}, \mathrm{N}, \mathrm{O}$ or $\mathrm{P}$ ) were prepared without ligands by one-step reduction method. Briefly, a suspension of $40 \mathrm{mg}$ of carbon support in $8 \mathrm{~mL}$ of anhydrous ethanol was prepared by sonicating at room temperature for 30 minutes. Subsequently, 2 $\mathrm{mL} \mathrm{K}_{2} \mathrm{PdCl}_{4}(9.72 \mathrm{mM})$ aqueous solution was added into the suspension gradually under ultrasonic conditions, holding for another 2 hours. Then, $1 \mathrm{~mL}$ deionized water containing $15 \mathrm{mg}$ $\mathrm{NaBH}_{4}$ was added to this black suspension to reduce Pd precursor to form metal Pd for another 40 minutes. Finally, the black mixture was filtered and washed with deionized water three times. After being dried in a vacuum oven at $80^{\circ} \mathrm{C}$ for $8 \mathrm{~h}$, we obtained Pd nanoparticles supported on carbon materials termed as Pd-CNHs Pd-OCNHs, Pd-NCNHs, Pd-BCNHs and PdPCNHs, respectively.

\section{Characterization}

The morphologies of samples were characterized by transmission electron microscopy (TEM) at an accelerating voltage of $200 \mathrm{kV}$ (JEOL-2100). The Pd content in the catalysts were tested by inductively coupled plasma-atomic emission spectrometer (ICP, Prodigy 7). The chemical states of elements and the content in the samples were examined by X-ray photoelectron spectroscopy (XPS, Axis Ultra). Raman measurements were conducted using a $530 \mathrm{~nm}$ laser in the back-scattering configuration on a Jobin-Yvon HR800 Spectrometer to obtain the contents of defect in the samples. The Brunauer-Emmett-Teller (BET) method was used to determine the specific surface area by measuring the adsorption of $\mathrm{N}_{2}$ using an ASAP2010 volumetric adsorption analyzer. The X-ray diffraction (XRD) patterns were recorded on a Rigaku MiniFlex 600 using filtered $\mathrm{Cu} \mathrm{K} \alpha$ radiation. Fourier transform infrared (FT-IR) spectra of samples in the range of $400-4000 \mathrm{~cm}^{-1}$ were investigated with an infrared spectrometric analyzer (Tensor 27, Bruker). Thermogravimetric analysis (TGA) was performed on a Q600 thermogravimetric analyzer (Thermal Analysis Inc., USA) from room temperature to $1000{ }^{\circ} \mathrm{C}$ at a rate of $10{ }^{\circ} \mathrm{C} \min ^{-1}$ under an air flow of $100 \mathrm{~mL}$ $\min ^{-1}$.

\section{Catalytic tests}

The dehydrogenation reaction of indoline to indole was carried out in a sealed pressure tube equipped with a reflux condenser. A typical procedure was as follows: $0.06 \mathrm{~g}(0.5 \mathrm{mmol})$ indoline, $50 \mathrm{mg}$ catalyst, $5 \mathrm{~mL}$ toluene, and $0.06 \mathrm{~g}$ dodecane (the internal standard) were placed in a sealed pressure tube. After stirring the heterogeneous mixture at $110{ }^{\circ} \mathrm{C}$ or $90^{\circ} \mathrm{C}$ for $1 \mathrm{~h}$, the catalyst was removed by filtration. The filtrate was analysed by AgilentGC7820A equipped with a HP-5 column and a FID detector. Each reaction was repeated three times.

\section{Results and discussion}

Fig. 1A showed CNHs and OCNHs exhibited dahlia-type with a diameter of $c a$. 50-100 nm and Pd NPs with a diameter of 2$3 \mathrm{~nm}$ were uniformly dispersed on CNHs or OCNHs. However, for doped CNHs with B, N and P atoms, Pd NPs prefer to load on CNHs of bud-type. As shown in Fig. S1 and Table S1, $\dagger$ the specific surface area of Pd-OCNHs $\left(697.4 \mathrm{~m}^{2} \mathrm{~g}^{-1}\right)$ was larger than Pd-CNHs $\left(672.5 \mathrm{~m}^{2} \mathrm{~g}^{-1}\right)$, Pd-BCNHs $\left(355.7 \mathrm{~m}^{2} \mathrm{~g}^{-1}\right)$, PdNCNHs $\left(475.4 \mathrm{~m}^{2} \mathrm{~g}^{-1}\right)$ and Pd-PCNHs $\left(578.9 \mathrm{~m}^{2} \mathrm{~g}^{-1}\right)$. In addition, the Pd content in the catalysts were shown in Table 1, PdOCNHs had the highest content of Pd species (9.99 wt\%) among the five catalysts due to its larger specific surface area, which has more nanospaces and nanowindows that are in favour of the tailoring of Pd NPs.

Furthermore, XRD diffraction patterns of samples in the samples were shown in Fig. 2. All samples exhibited the diffraction characteristic peaks of carbon as well as $\mathrm{Pd}$ 


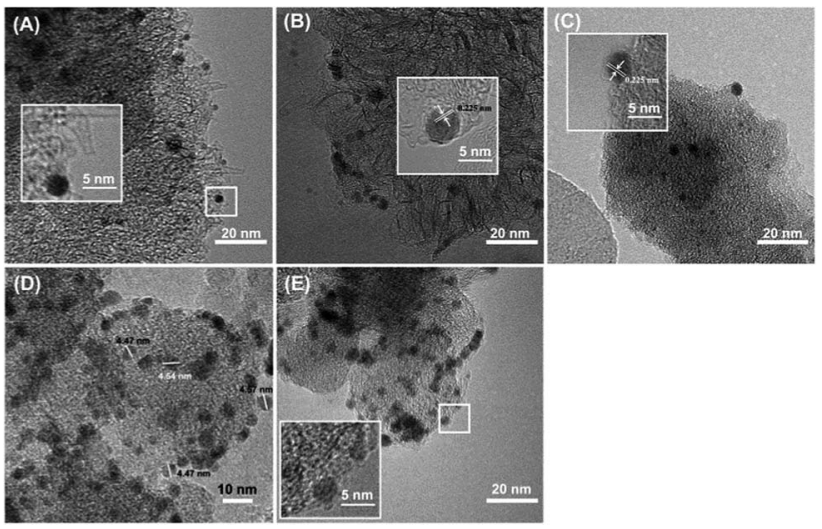

Fig. 1 TEM images of (A) Pd-CNHs, (B) Pd-OCNHs, (C) Pd-BCNHs, (D) $\mathrm{Pd}-\mathrm{NCNHs}$, and (E) Pd-PCNHs, respectively, insets show Pd NPs at a high magnification.

diffraction peaks. The diffraction peaks at $26.35,42.77$ and $54.66^{\circ}$ are correspondent with the (002), (100) and (004) facet of $\mathrm{CNHs},{ }^{40}$ respectively. The new peaks at $40.00,46.63$ and $68.19^{\circ}$ in Pd-XCNHs are respectively ascribed to the (111), (200) and (220) facet of Pd face-centered cubic (FCC) structure. ${ }^{\mathbf{4 1 , 4 2}}$ The lattice $d$-spacing of (111) plane calculated is approximately $0.225 \mathrm{~nm}$ according to Bragg's law, ${ }^{43}$ which is confirmed by HRTEM in Fig. 1B and C. The peak representing Pd (111) was recognized clearly so that it was used to estimate the crystalline size. According to Debye-Scherrer method, the relationship between the average size of particles and the full width at a half max (FWHW) of diffraction peak is inversely proportional. ${ }^{44} \mathrm{Pd}-$ NCNHs had the smallest FWHW among the samples, and hence the largest size of Pd NPs. This result was consistent well with the result of TEM, where the Pd NPs with a diameter of 4-5 nm were uniformly loaded on NCNHs (Fig. 1D).

Subsequently, the chemically structural features of samples were investigated by FT-IR spectroscopy. The characteristic peaks of Pd-XCNHs in Fig. 3A were nearly the same, which implied that Pd-XCNHs had the similar framework structures and functional groups. The band at $1720 \mathrm{~cm}^{-1}$ was assigned to ketonic $\mathrm{C}=\mathrm{O}$ groups in the samples. ${ }^{45,46}$ It has been reported that ketonic $\mathrm{C}=\mathrm{O}$ is considered to be an active site of $\mathrm{C}-\mathrm{H}$ by coordinating with $\mathrm{C}-\mathrm{H}$ bond, ${ }^{47}$ which could improve the catalytic activity of the reactions involving activation of $\mathrm{C}-\mathrm{H}$ bonds. Moreover, the Raman spectroscopy was used to study the surface defects of the sample. As shown in Fig. 2B, the G band at approximately $1590 \mathrm{~cm}^{-1}$ and the $\mathrm{D}$ band at near $1350 \mathrm{~cm}^{-1}$ are the graphitic carbon peaks and the disordered carbon peaks, ${ }^{\mathbf{4 8 , 4 9}}$ respectively. The higher $I_{\mathrm{D}} / I_{\mathrm{G}}$ ratio in doping CNHs implies the more defect and disordered carbon of sample. ${ }^{50-52}$ Pd-BCNHs

Table 1 The Pd content in the catalysts were determined by ICP

\begin{tabular}{llllll}
\hline Sample & Pd-CNHs & Pd-OCNHs & Pd-BCNHs & Pd-NCNHs & Pd-PCNHs \\
\hline $\begin{array}{l}\text { Pd content } \\
\text { (wt } \% \text { ) }\end{array}$ & 4.69 & 9.99 & 5.61 & 5.63 & 5.63
\end{tabular}

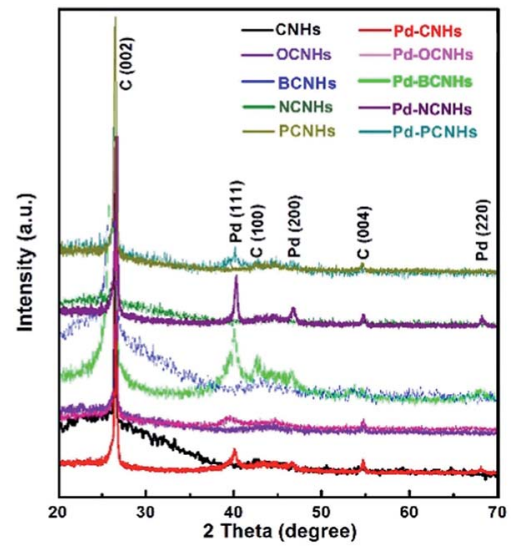

Fig. 2 XRD diffraction patterns of samples.

$\left(I_{\mathrm{D}} / I_{\mathrm{G}}=1.17\right), \operatorname{Pd}-\mathrm{NCNHs}\left(I_{\mathrm{D}} / I_{\mathrm{G}}=1.20\right)$, Pd-OCNHs $\left(I_{\mathrm{D}} / I_{\mathrm{G}}=\right.$ 1.47) and Pd-PCNHs $\left(I_{\mathrm{D}} / I_{\mathrm{G}}=1.32\right)$ had more defective carbon compared with Pd-CNHs $\left(I_{\mathrm{D}} / I_{\mathrm{G}}=1.06\right)$. Indeed, Pd-OCNHs, PdNCNHs and Pd-PCNHs also showed the obvious peaks originating from X-doped defective carbon at 439,467 and $532{ }^{\circ} \mathrm{C}$ in DTG curves (see Fig. S2 $\dagger$ ), ${ }^{38}$ respectively. Raman and TGA characterizations indicated that heteroatom doped CNHs had more defective carbon compared with pure CNHs, which could affect the reaction activity. ${ }^{47}$

The surface state and chemical composition of samples were studied by X-ray photoelectron spectroscopy (XPS). The relative surface concentrations of the individual elements are shown in Table S2. $\uparrow$ The XPS spectra of Pd 3d of five catalysts are shown in Fig. 4A. $\mathrm{Pd} 3 \mathrm{~d}^{5 / 2}(335.8 \mathrm{eV}), \mathrm{Pd} 3 \mathrm{~d}^{3 / 2}(341.1 \mathrm{eV})$ and $\mathrm{Pd} 3 \mathrm{~d}^{5 / 2}$ (337.2 eV), $\mathrm{Pd} 3 \mathrm{~d}^{3 / 2}(342.4 \mathrm{eV})$ were assigned to $\mathrm{Pd}^{0}$ and $\mathrm{Pd}^{2+}, 53,54$ respectively. The presence of characteristic peaks of $\mathrm{Pd} 3 \mathrm{~d}$ in Fig. 4A unambiguously demonstrated that Pd NPs had been successfully loaded on CNHs. In the Table $\mathrm{S} 3, \dagger$ Pd-OCNHs (61.73\%) and Pd-BCNHs $(60.88 \%)$ contained more $\mathrm{Pd}^{0}$ than Pd-CNHs (32.95\%), Pd-NCNHs (32.54\%) and Pd-PCNHs $(33.51 \%)$ in the surface of samples. Some previous studies have been reported that $\mathrm{Pd}^{0}$ plays a vital role in dehydrogenation of indoline. ${ }^{11,12}$ In the B 1s spectra, the peaks at 186.7, 188.3 and $193.3 \mathrm{eV}$ can be respectively ascribed to $\mathrm{B}-\mathrm{C}_{4}, \mathrm{~B}-\mathrm{C}_{3}$ and $\mathrm{B}-$ $\mathrm{O},{ }^{38,55}$ and the peak at $188.3 \mathrm{eV}$ indicated that the $\mathrm{B}$ element enters the graphite sheet lattice. Two kinds of $\mathrm{N}$ species including pyridinic $\mathrm{N}(398.7 \mathrm{eV})$ and pyrrolic $\mathrm{N}(400.2 \mathrm{eV})^{56}$ were found in the Pd-NCNHs in Fig. 4D. The peak at $133.4 \mathrm{eV}$ and $135.5 \mathrm{eV}$ in the Fig. $4 \mathrm{E}$ could be derived respectively from $\mathrm{P}-\mathrm{C}$ and $\mathrm{P}-\mathrm{O}$ of Pd-PCNHs. ${ }^{38,55}$ These results indicated the boron, nitrogen atom, and phosphorus atoms had been doped into the corresponding materials carbon materials successfully. As we can see, Fig. 4B showed four peaks corresponding to oxygen atoms of carboxyl (534.3-535.4 eV), ether oxygen atoms in esters and anhydrides (533.1-533.8 eV), $\mathrm{C}=\mathrm{O}$ in esters, amides, anhydrides and $\mathrm{O}$ atoms in hydroxyl or ethers (532.3-532.8 eV), and ketonic $\mathrm{C}=\mathrm{O}$ groups (531.0-531.5 eV). ${ }^{56,57}$ Oxygencontaining functional groups in Pd-CNHs, Pd-BCNHs, PdNCNHs and Pd-PCNHs were mainly derived from CO during the carbon nanomaterials synthesis. Pd-OCNHs had the highest 

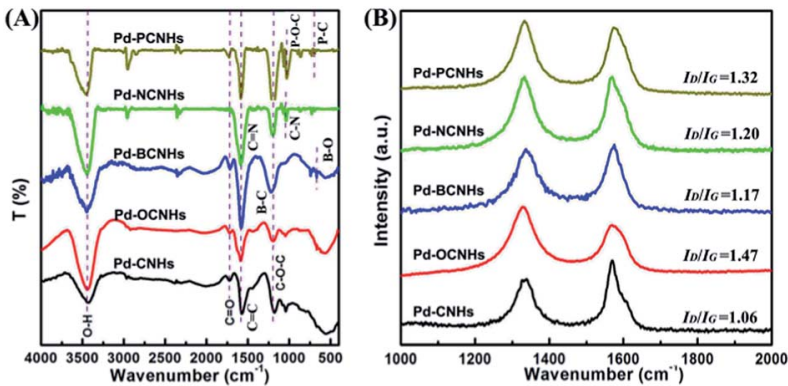

Fig. 3 (A) FT-IR spectra of the samples; (B) Raman spectra of the catalysts, the $I_{D} / I_{G}$ represent the intensity ratio of $D$ band and $G$ band of catalysts, respectively.

content of ketonic $\mathrm{C}=\mathrm{O}$ groups (about 25\%) in the surface due to mixed acid oxidation.

Finally, we investigated the catalytic capabilities of Pd catalysts for dehydrogenation of indoline at $110{ }^{\circ} \mathrm{C}$. As shown in Table 2, Pd-XCNHs all exhibited high catalytic activities (conversion rate: 100\%; yield: $>99 \%$ ) without adding any oxidants, which were being widely used in the previously reported catalysts (e.g. $\mathrm{Ru} / \mathrm{Co}_{3} \mathrm{O}_{4},{ }^{7}$ AuNPs/C, ${ }^{9}$ and $\mathrm{Pd}_{3} \mathrm{~Pb} / \mathrm{Al}_{2} \mathrm{O}_{3}$ (ref. 12)) under the same temperature $\left(110{ }^{\circ} \mathrm{C}\right)$, while other catalysts (e.g. AuNPs/C, $\mathrm{Ru} / \mathrm{Co}_{3} \mathrm{O}_{4}$ and $\mathrm{Cu} / \mathrm{Al}_{2} \mathrm{O}_{3}$ (ref. 58)) were reported involving either $\mathrm{O}_{2}$ or shielding gas (e.g. $\mathrm{N}_{2}$ and $\mathrm{Ar}$ ). To further explore the role of the catalysts in the mechanism, catalytic activities of Pd NPs supported on the different heteroatoms-doped CNHs, Pd-BCNHs, Pd-NCNHs Pd-OCNHs and Pd-PCNHs, were investigated at low temperature of $90{ }^{\circ} \mathrm{C}$. As shown in Table 3, Pd-OCNHs $\left(61.73 \% \mathrm{Pd}^{0}\right)$ showed the highest catalytic activity at $90{ }^{\circ} \mathrm{C}$ among the above catalysts and obtained a high conversion rate (100\%) and yield (93\%), while
Table 2 The dehydrogenation of indoline to indole using the various catalysts at $110{ }^{\circ} \mathrm{C}^{a}$

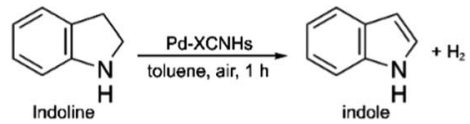

\begin{tabular}{llll}
\hline Entry & Catalyst & Conv. (\%) & Yield (\%) \\
\hline 1 & None & 19 & 9 \\
2 & K$_{2}$ PdCl $_{4}$ & 100 & 45 \\
3 & CNHs & 32 & 22 \\
4 & OCNHs & 44 & 22 \\
5 & BCNHs & 46 & 30 \\
6 & NCNHs & 32 & 21 \\
7 & PCNHs & 32 & 18 \\
8 & Pd-CNHs & 100 & $>99$ \\
9 & Pd-OCNHs & 100 & $>99$ \\
10 & Pd-BCNHs & 100 & $>99$ \\
11 & Pd-NCNHs & 100 & $>99$ \\
12 & Pd-PCNHs & 100 & $>99$
\end{tabular}

${ }^{a}$ Reaction conditions: substrate, $0.5 \mathrm{mmol}$; catalyst, $50 \mathrm{mg}$; solvent, 5 $\mathrm{mL}$ (toluene); temperature, $110{ }^{\circ} \mathrm{C}$; time, $1 \mathrm{~h}$.

Pd-BCNHs $\left(60.88 \% \mathrm{Pd}^{0}\right)$, Pd-CNHs $\left(32.95 \% \mathrm{Pd}^{0}\right)$, Pd-NCNHs $\left(32.54 \% \mathrm{Pd}^{0}\right), \mathrm{Pd}-\mathrm{PCNHs}\left(33.51 \% \mathrm{Pd}^{0}\right)$ and $\mathrm{K}_{2} \mathrm{PdCl}_{4}\left(0 \% \mathrm{Pd}^{0}\right)$ obtained 66, 54, 45, 17 and 9\% yield, respectively. These results indicated that $\mathrm{Pd}^{0}$ species play a crucial role during the dehydrogenation process.

Based on the above results and previously researches, ${ }^{7,9,12}$ we speculated a possible catalytic mechanism for the composites in dehydrogenation of indoline in Scheme 1. Firstly, the $\mathrm{N}$ atom of indoline coordinated to the $\mathrm{Pd}^{0}{ }^{59}$ Then, $\mathrm{C}-\mathrm{H}$ bond adjacent to the $\mathrm{N}$ atom was activated. ${ }^{11}$ Subsequently, the intermediate
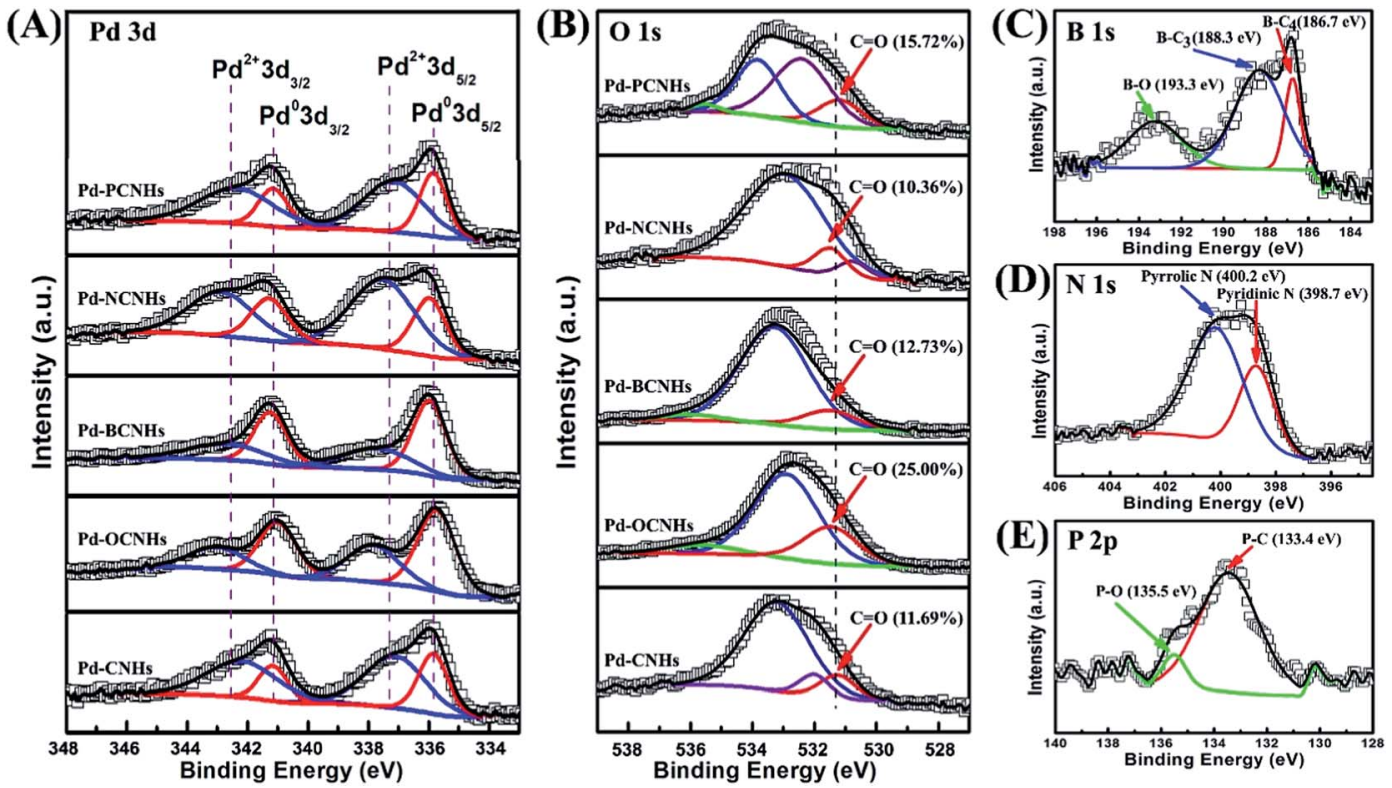

Fig. 4 (A) Pd 3d XPS spectra of catalysts; (B) O 1s XPS spectra of catalysts; (C) B 1s XPS spectra of Pd-BCNHs; (D) N 1s XPS spectra of Pd-NCNHs; (E) P 2p XPS spectra of Pd-PCNHs. 
Table 3 The dehydrogenation of indoline to indole using the various catalysts at $90^{\circ} \mathrm{C}^{a}$

\begin{tabular}{|c|c|c|c|}
\hline Entry & Catalyst & Conv. (\%) & Yield (\%) \\
\hline 1 & None & 17 & 8 \\
\hline 2 & $\mathrm{~K}_{2} \mathrm{PdCl}_{4}$ & 15 & 9 \\
\hline 3 & CNHs & 28 & 19 \\
\hline 4 & OCNHs & 39 & 24 \\
\hline 5 & BCNHs & 33 & 20 \\
\hline 6 & NCNHs & 29 & 18 \\
\hline 7 & PCNHs & 21 & 15 \\
\hline 8 & Pd-CNHs & 71 & 54 \\
\hline 9 & Pd-OCNHs & 100 & 93 \\
\hline 10 & Pd-BCNHs & 81 & 66 \\
\hline 11 & Pd-NCNHs & 56 & 45 \\
\hline 12 & Pd-PCNHs & 25 & 17 \\
\hline
\end{tabular}

${ }^{a}$ Reaction conditions: substrate, $0.5 \mathrm{mmol}$; catalyst, $50 \mathrm{mg}$; solvent, 5 $\mathrm{mL}$ (toluene); temperature, $90^{\circ} \mathrm{C}$; time, $1 \mathrm{~h}$.

species underwent $\beta$-hydride elimination to form indole. ${ }^{9}$ Finally, hydrogen species was removed by oxygen. ${ }^{12}$ Although the interaction between the aromatic ring of indoline and the $\pi$ electron of the CNHs may be weak, it could not be ignored because the $\pi \cdots \pi$ interaction favours the adsorption of indoline in planar fashion. The similar argument has been reported in the study for Pd@carbon nitride catalysing hydrogenation of phenol. ${ }^{60}$

It is noteworthy that metal-free CNHs (BCNHs, NCNHs, OCNHs and PCNHs) also had catalytic activities (in Table 2), and the yield increased with increasing ketonic $\mathrm{C}=\mathrm{O}$ content from $18 \%$ (NCNHs, $10.36 \% \mathrm{C}=\mathrm{O}$ ) through 19\% (CNHs, 11.69\% $\mathrm{C}=\mathrm{O}$ ) and $20 \%$ (BCNHs, $12.73 \% \mathrm{C}=\mathrm{O}$ ) to $24 \%$ (OCNHs, $25.00 \% \mathrm{C}=\mathrm{O})$. Nevertheless, PCNHs $(15.72 \% \mathrm{C}=\mathrm{O})$ only achieved a yield of $15 \%$. Combining with results of Raman, XPS and TGA characterizations, we speculate two reasons to clarify this contradiction. On one hand, PCNHs holds more surface defects by the introduction of $\mathrm{P}$ atoms than BCNHs and NCNHs do, which reduces the flatness of CNHs and weakens the $\pi \cdots \pi$ interaction between $\mathrm{CNHs}$ and indoline, leading to the

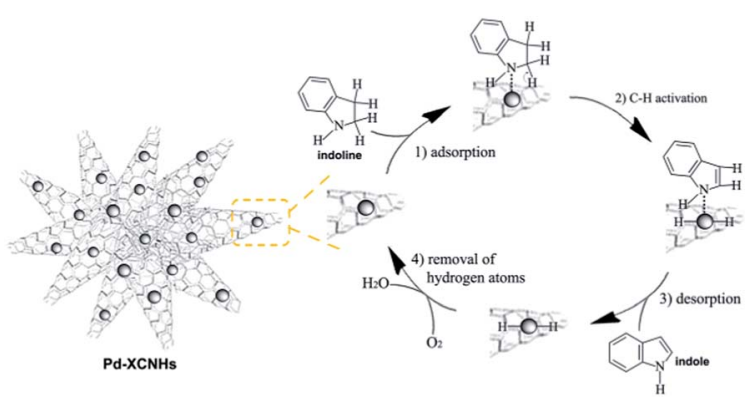

Scheme 1 The proposed reaction mechanism of Pd supported on doped $\mathrm{CNHs}$. inhibited activity of PCNHs. In this regard, although Pd-CNHs, Pd-NCNHs and Pd-PCNHs had nearly equivalent proportion of $\mathrm{Pd}^{0}$, Pd-PCNHs $\left(I_{\mathrm{D}} / I_{\mathrm{G}}=1.32\right)$ with more defective carbon exhibited lower activity for dehydrogenation of indoline. On the other hand, the surface of OCNHs has rich ketonic $\mathrm{C}=\mathrm{O}$, a nucleophilic species, which preferentially reacts with electrondeficient saturated bonds and promotes the activation of $\mathrm{C}-\mathrm{H}^{47}$ adjacent to the nitrogen atom, resulting in higher activity than those of other metal-free CNHs. Thus, although Pd-OCNHs and Pd-BCNHs had the approximate content of $\mathrm{Pd}^{0}$, Pd-OCNHs containing lots of ketonic $\mathrm{C}=\mathrm{O}$ showed higher activity than Pd-BCNHs does. Based on the above discussion, we believe that $\mathrm{Pd}^{0}$ is the main active site for adsorption of indoline during the catalytic process, and ketonic $\mathrm{C}=\mathrm{O}$ of OCNHs is the active groups for $\mathrm{C}-\mathrm{H}$ bond activation. Therefore, the excellent catalytic activity of Pd-OCNHs in dehydrogenation of indoline is the result of synergistic action between metal palladium and OCNHs.

It is noteworthy that although CNTs is similar to CNHs in structure, CNTs produced by chemical vapor deposition (CVD) or other methods may contain some ineradicable metalimpurities (such as $\mathrm{Ni}^{\mathbf{6 1}}$ or $\mathrm{Fe}^{61,62}$, et al.), resulting in more complicated reaction mechanism. Indeed, iron oxide component has been reported to catalyse dehydrogenating of indoline. ${ }^{\mathbf{1 4}}$ Thus, metal impurity-free Pd-OCNHs here is a more suitable paradigm to investigate the catalytic mechanism for dehydrogenation of indoline.

\section{Conclusions}

In summary, we have successfully synthesized Pd NPs with diameter of 2-3 nm dispersed uniformly on B-, N-, O-, P-doped CNHs without ligands via one-step reduction method. PdOCNHs contained high content of palladium species due to large BET specific surface area and exhibited the highest catalytic activity among all the catalysts in the dehydrogenating of indoline to indole. These results indicate that the remarkable activity of Pd-OCNHs originates in synergistic effect between metal palladium and OCNHs. Metal palladium is the main active site for adsorption of indoline during the catalytic process, OCNHs with lots of ketonic $\mathrm{C}=\mathrm{O}$ not only acts as a carrier, but also provides the active groups (ketonic $\mathrm{C}=\mathrm{O}$ ) for $\mathrm{C}-\mathrm{H}$ bond activation of reactant to improve the catalytic activity. We believe that the Pd-OCNHs here can also be applied to dehydrogenation of other heterocycles as catalyst with outstanding catalytic activity.

\section{Acknowledgements}

We gratefully thank NSF of China (No. 21471010) and the Ministry of Science and Technology of China (No. 2013CB933402) for generously supporting this work.

\section{Notes and references}

1 R. J. Sundberg, The chemistry of indoles, Academic Press, NewYork, 1970. 
2 M. N. Preobrazhenskaya, Russ. Chem. Rev., 1967, 36, 753.

3 U. Tilstam, M. Harre, T. Heckrodt and H. Weinmann, Tetrahedron Lett., 2001, 42, 5385.

4 T. Mukaiyama, A. Kawana, Y. Fukuda and J. Matsuo, Chem. Lett., 2001, 390.

5 A. B. A. Jansen, J. M. Johnson and J. R. J. Surtees, J. Chem. Soc., 1964, 5573.

6 K. Yamaguchi and N. Mizuno, Angew. Chem., Int. Ed., 2003, 42, 1480.

7 F. Li, J. Chen, Q. Zhang and Y. Wang, Green Chem., 2008, 10, 553.

8 K. Kamata, J. Kasai, K. Yamaguchi and N. Mizuno, Org. Lett., 2004, 6, 3577.

9 M.-H. So, Y. Liu, C.-M. Ho and C.-M. Che, Chem.-Asian J., 2009, 4, 1551.

10 L. Aschwanden, T. Mallat, F. Krumeich and A. Baiker, J. Mol. Catal. A: Chem., 2009, 309, 57.

11 T. Hara, K. Mori, T. Mizugaki, K. Ebitani and K. Kaneda, Tetrahedron Lett., 2003, 44, 6207.

12 S. Furukawa, A. Suga and T. Komatsu, Chem. Commun., 2014, 50, 3277.

13 D. V. Jawale, E. Gravel, N. Shah, V. Dauvois, H. Li, I. N. N. Namboothiri and E. Doris, Chem.-Eur. J., 2015, 21, 7039.

14 X. Cui, Y. Li, S. Bachmann, M. Scalone, A.-E. Surkus, K. Junge, C. Topf and M. Beller, J. Am. Chem. Soc., 2015, 137, 10652.

15 P. Nikolaev, M. J. Bronikowski, R. K. Bradley, F. Rohmund, D. T. Colbert, K. A. Smith and R. E. Smalley, Chem. Phys. Lett., 1999, 313, 91.

16 Y. Tao, D. Noguchi, C.-M. Yang, H. Kanoh, H. Tanaka, M. Yudasaka, S. Iijima and K. Kaneko, Langmuir, 2007, 23, 9155.

17 S. Ustsumi, K. Urita, H. Kanoh, M. Yudasaka, K. Suenaga, S. Iijima and K. Kaneko, J. Phys. Chem. B, 2006, 110, 7165.

18 V. Krungleviciute, A. D. Migone and M. Pepka, Carbon, 2009, 47, 769.

19 R. Yuge, T. Ichihashi, Y. Shimakawa, Y. Kubo, M. Yudasaka and S. Iijima, Adv. Mater., 2004, 16, 1420.

20 T. Azami, D. Kasuya, R. Yuge, M. Yudasaka, S. Iijima, T. Yoshitake and Y. Kubo, J. Phys. Chem. C, 2008, 112, 1330.

21 S. Utsumi, J. Miyawaki, H. Tanaka, Y. Hattori, T. Itoi, N. Ichikuni, H. Kanoh, M. Yudasaka, S. Iijima and K. Kaneko, J. Phys. Chem. B, 2005, 109, 14319.

22 E. Bekyarova, A. Hashimoto, M. Yudasaka, Y. Hattori, K. Murata, H. Kanoh, D. Kasuya, S. Iijima and K. Kaneko, J. Phys. Chem. B, 2005, 109, 3711.

23 R. Yuge, T. Ichihashi, Y. Shimakawa, Y. kubo, M. Yudasaka and S. Iijima, Adv. Mater., 2004, 16, 1420.

24 T. Itoh, K. Urita, E. Bekyarova, M. Arai, M. Yudasaka, S. Iijima, T. Ohba, K. Kaneko and H. Kanoh, J. Colloid Interface Sci., 2008, 322, 209.

25 R. Yuge, T. Ichihashi, J. Miyawaki, T. Yoshitake, S. Iijima and M. Yudasaka, J. Phys. Chem. C, 2009, 113, 2741.

26 J. Fan, M. Yudasaka, Y. Kasuya, D. Kasuya and S. Iijima, Chem. Phys. Lett., 2004, 397, 5.
27 N. Sano, K. Taniguchi and H. Tamon, J. Phys. Chem. C, 2014, 118, 3402.

28 K. Ajima, A. Maigne, M. Yudasaka and S. Iijima, J. Phys. Chem. B, 2006, 110, 19097.

29 M. Kosaka, S. Kuroshima, K. Kobayashi, S. Sekino, T. Ichihashi, S. Nakamura, T. Yoshitake and Y. Kubo, J. Phys. Chem. C, 2009, 113, 8660.

30 K. Murata, M. Yudasaka and S. Iijima, Carbon, 2006, 44, 799. 31 T. Koshitake, Y. Shimakawa, S. Kuroshima, H. Kimura, T. Ichihashi, Y. Kubo, D. Kasuya, K. Takahashi, F. Kokai, M. Yudasaka and S. Iijima, Phys. B, 2002, 323, 124.

32 A. H. M. de Vries, J. M. C. A. Mulders, J. H. M. Mommers, H. J. W. Henderickx and J. G. de Vries, Org. Lett., 2003, 5, 3285 .

33 S. Zhu and G. Xu, Nanoscale, 2010, 2, 2538.

34 N. Karousis, T. Ichihashi, M. Yudasaka, S. Iijima and N. Tagmatarchis, J. Nanosci. Nanotechnol., 2009, 9, 6047.

35 T. Itoh, H. Danjo, W. Sasaki, K. Urita, E. Bekyarova, M. Arai,

T. Imamoto, M. Yudasaka, S. Iijima, H. Kanoh and K. Kaneko, Carbon, 2008, 46, 172.

36 J. G. de Vries, Dalton Trans., 2006, 421.

37 N. Li, Z. Wang, K. Zhao, Z. Shi, Z. Gu and S. Xu, Carbon, 2010, 48, 1580.

38 X. Wu, L. Cui, P. Tang, Z. Hu, D. Ma and Z. Shi, Chem. Commun., 2016, 52, 5391.

39 L. Cui, Y. Liu, X. Wu, Z. Hu, Z. Shi and H. Li, RSC Adv., 2015, 5, 75817.

40 T. A. Saleh, Appl. Surf. Sci., 2011, 257, 7746.

41 Y. Yan, X. Jia and Y. Yang, Catal. Today, 2016, 259, 292.

42 C. Poonjarernsilp, N. Sano, T. Charinpanitkul, H. Mori,

T. Kikuchi and H. Tamon, Carbon, 2011, 49, 4920.

43 F. Wolfers, C. R. Hebd. Seances Acad. Sci., 1923, 177, 759.

44 B. D. Hall, D. Zanchet and D. Ugarte, J. Appl. Crystallogr., 2000, 1335.

45 N. Kizilcan and B. Erson, Pigm. Resin Technol., 2015, 44, 198.

46 J. Y. Kim, S. Morisada, H. Kawakita, K. Ohto and Y. Kim, J. Inclusion Phenom. Macrocyclic Chem., 2015, 82, 25.

47 J. Zhang, X. Liu, R. Blume, A. Zhang, R. Schlögl and D. S. Su, Science, 2008, 322, 73.

48 A. Malesevic, R. Vitchev, K. Schouteden, A. Volodin, L. Zhang, G. V. Tendeloo, A. Vanhulsel and C. V. Haesendonck, Nanotechnology, 2008, 19, 305604.

49 F. Parvizi, D. Teweldebrhan, S. Ghosh, I. Calizo, A. A. Balandin, H. Zhu and R. Abbaschian, Micro Nano Lett., 2008, 3, 29.

50 D. Y. Kim, C.-M. Yang, H. Noguchi, M. Yamamoto, T. Ohba, H. Kanoh and K. Kaneko, Carbon, 2008, 46, 611.

51 Z.-H. Sheng, H.-L. Gao, W.-J. Bao, F.-B. Wang and X.-H. Xia, J. Mater. Chem., 2012, 22, 390.

52 C.-W. Tsai, M.-H. Tu, C.-J. Chen, T.-F. Hung, R.-S. Liu, W.-R. Liu, M.-Y. Lo, Y.-M. Peng, L. Zhang, J. Zhang, D.-S. Shy and X.-K. Xing, RSC Adv., 2011, 1, 1349.

53 H. Jin, T. Xiong, Y. Li, X. Xu, M. Li and Y. Wang, Chem. Commun., 2014, 50, 12637.

54 X. Xu, Y. Li, Y. Gong, P. Zhang, H. Li and Y. Wang, J. Am. Chem. Soc., 2012, 134, 16987. 
55 P. Tang, G. Hu, Y. Gao, W. Li, S. Yao, Z. Liu and D. Ma, Sci. Rep., 2014, 4, 1.

56 L. Sun, C. Wang, Y. Zhou, X. Zhang, B. Cai and J. Qiu, Appl. Surf. Sci., 2013, 277, 88.

57 J.-H. Zhou, Z.-J. Sui, J. Zhu, P. Li, D. Chen, Y.-C. Dai and W.-K. Yuan, Carbon, 2007, 45, 785.

58 D. Damodara, R. Arundhathi and P. R. Likhar, Adv. Synth. Catal., 2014, 356, 189.
59 S.-I. Murahashi, N. Yoshimura, T. Tsumiyama and T. Kojima, J. Am. Chem. Soc., 1983, 105, 5002.

60 Y. Wang, J. Yao, H. Li, D. Su and M. Antonietti, J. Am. Chem. Soc., 2011, 133, 2362.

61 D. Yuan, L. Ding, H. Chu, Y. Feng, T. P. McNicholas and J. Liu, Nano Lett., 2008, 8, 2576.

62 P. Nikolaev, M. J. Bronikowski, R. K. Bradley, F. Rohmund, D. T. Colbert, K. A. Smith and R. E. Smalley, Chem. Phys. Lett., 1999, 313, 91. 